\title{
Subglacial comminution in till - evidence from microfabric studies and grain-size distributions
}

\author{
Yi ChaOlu \\ Laboratory of Environmental Sciences, Institute of Geodesy and Geophysics, Academica Sinica, Wuhan 430077, China
}

\begin{abstract}
Quartz, feldspar and chlorite, the principal minerals in a basal till from the Halasi River catchment in the Altay Mountains, northwestern China, are present in approximately equal concentrations in the coarse fraction of the till, $1.0-0.125 \mathrm{~mm}$. Quartz concentrations are significantly higher than those of the other two minerals in the 0.125 $0.016 \mathrm{~mm}$ size range. Feldspar and chlorite concentrations are higher than those of quartz in the finest fraction. Quartz has a strong preferred mode at $0.063-0.032 \mathrm{~mm}$. Feldspar and chlorite have two weak modes in the silt-size range, one between 0.063 and $0.032 \mathrm{~mm}$ and the other between 0.016 and $0.004 \mathrm{~mm}$.

Thin sections of oriented impregnated samples were used to study crushing and abrasion. Over 2700 daughter particles were identified as products of comminution of 925 parent grains. Quartz and feldspar are most likely to be broken into two particles of roughly equal size, as are fine chlorite grains. However, owing to their weakness and cleavage, larger grains of chlorite tend to be split into more than two daughter particles.

Sizes of the daughter grains were measured and sizes of the original parent grains were estimated. Mean parent grain-sizes for quartz, feldspar and chlorite are 0.129, 0.078 and $0.059 \mathrm{~mm}$, respectively, whereas mean daughter grain-sizes are $0.068,0.041$ and $0.024 \mathrm{~mm}$, respectively. The greater percentage reduction in the size of chlorite reflects its tendency to break into more than two daughter particles.

Most grains tend to be crushed. Only a few large particles seem to have suffered from abrasion.
\end{abstract}

\section{INTRODUGTION}

Comminution of sediment grains is an important subglacial process. Many authors (Dreimanis and Vagners, 1971, 1972; Boulton, 1978; Haldorsen, 1981) have attributed a mode in the silt-size range in till to such comminution, and Drake (1972) inferred that a change in roundness of pebbles with increasing distance from their source in east-central New Hampshire was a result of it.

In studies of the size distributions of various mineral species in till, Dreimanis and Vagners (1971) suggested that quartz and feldspar can be reduced to a terminal grain-size of $0.062-0.031 \mathrm{~mm}$, while other minerals might have smaller terminal sizes. Dilabio (1981) found that chalcopyrite in till in the Lac Mistassini-Lac Waconichi area of Quebec has a clast mode between 16 and $1 \mathrm{~mm}$ and a matrix mode from 0.063 to $0.016 \mathrm{~mm}$. Other researchers have studied comminution of quartz in till with the use of a scanning electron microscope (e.g. Krinsley and Doornkamp, 1973; Mahaney and others, 1988), and have observed what they infer to be abraded surfaces and conchoidal fracture resulting from subglacial comminution.

In discussing comminution, a distinction between crushing and abrasion is sometimes made. The word "crush" implies a process in which forces are predominantly normal to a grain surface, whereas abrasion suggests forces parallel to the surface. Clearly, there must be a continuum between these end members. However, shear forces are likely to dislodge small particles from the surface of a larger one, whereas normal forces break grains into daughter particles of roughly equal size. Herein, mineralogical analyses of different grain-size fractions from a basal till and microfabric studies of impregnated samples of the till are used to clarify the role of crushing and abrasion in controlling the grain-size distribution of the till matrix.

\section{REGIONAL SETTING}

The area from which the samples were obtained is in the Halasi River catchment on the south slope of the Altay Mountains in China $\left(48^{\circ} 30^{\prime}-49^{\circ} 20^{\prime} \mathrm{N}, 86^{\circ} 50^{\prime}-87^{\circ} 55^{\prime} \mathrm{E}\right.$ ). Elevations range from $\sim 1000 \mathrm{~m}$ in the river valley to $4374 \mathrm{~m}$ at the top of the highest peak, Youyifong. The modern snow line is $3000-3100 \mathrm{~m}$, so valley glaciers are present. Halasi Glacier, the largest and longest in the region, is over $10 \mathrm{~km}$ long. The snouts of modern glaciers are at elevations of 2300-2400 m, while the lower limit of known Quaternary glacial deposits is at $1300 \mathrm{~m}$.

Lateral moraines are present along the banks of Halasi Lake and three sets of end moraines are distributed over a distance of $3.5 \mathrm{~km}$ down-valley from the lake (Fig. 1). Each set of end moraines consists of several minor moraines. The till is $20-30 \mathrm{~m}$ thick in these moraines. Near the outlet of Halasi Lake, there are two small patches of basal till (or ground moraine) about $10 \mathrm{~m}$ thick, with little relief.

${ }^{14} \mathrm{C}$ dating of a secondary carbonate coating on till gravels on the valley floor near site B (Fig. 1) yielded an age of $4040 \pm 80$ years BP. This is considered to be a minimum age for the deposits. Accordingly, consistent with data on moraine ages in the other Chinese mountains, this deposit 

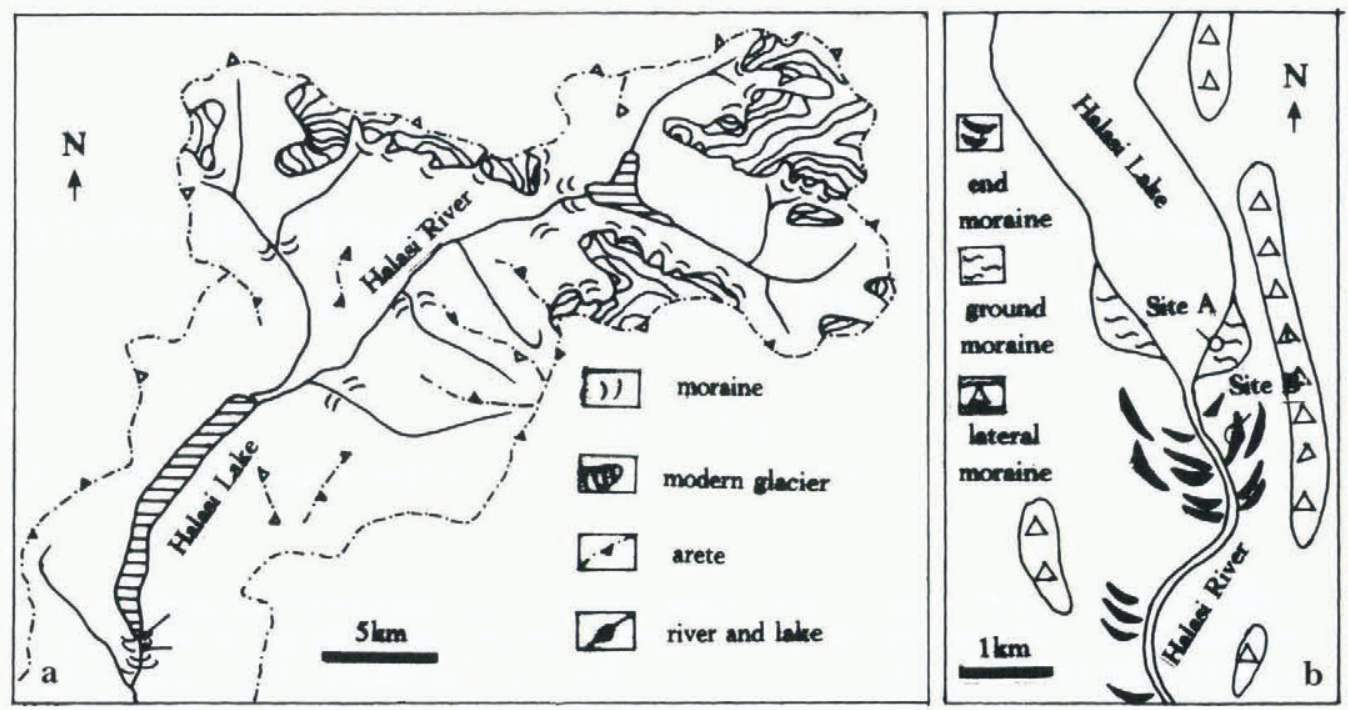

Fig. 1. Maps showing sampling sites. (a) Location map of the study area. (b) Geomorphological features of moraine in the vicinity of the outlet of Halasi Lake.

is believed to have been formed during the Last Glaciation in China (equivalent to the Wisconsinan or Weichselian) (Cui Zhijiu and others, 1992).

The bedrock in the glaciated area is predominantly granite and chlorite, chlorite-quartz and quartz-schists. Accordingly, over $90 \%$ of the mineral grains in the till are quartz, feldspar or chlorite (Table 1).

\section{GENERAL PROPERTIES OF THE TILL}

Tills near the outlet of Halasi River contain a large number of spherical clasts, believed to have come from ancient lacustrine sediments (Cui Zhijiu and others, 1992; Yi Chaolu and Cui Zhijiu, 1994). At site A (Fig. 1), the till is massive and compact, and the matrix has a high silt content. The till fabric is strong, with a preferred orientation of long axes parallel to the ice-flow direction and dipping up-glacier.

The till at site $\mathrm{B}$ is also massive but less compact and coarser. It contains lenticular layers of sand and silt, 0.18$0.50 \mathrm{~m}$ thick, with individual laminae that are $1-2 \mathrm{~mm}$ thick. The preferred orientation of gravel-sized clasts is perpendicular to the trend of the moraine.

\section{METHODS}

\section{Grain-size and mineralogical analyses}

Fourteen pairs of samples were collected, six from ground moraine near site $\mathrm{A}$, and eight from an end moraine near site B (Fig. 1). One sample from each pair was loose and was used for grain-size analysis, whereas the second was an oriented, impregnated sample which was thin-sectioned and used for microfabric studies.

Size distributions of grains $>0.039 \mathrm{~mm}$ were determined by sieving. Fractions $>0.125 \mathrm{~mm}$ were separated at $1 \phi$ intervals ( $\phi=\log _{2} d$ where $d$ is the grain-size in millimeters) and fractions between 0.125 and $0.039 \mathrm{~mm}$ were separated at $\frac{1}{4} \phi$ intervals.

The fine-sand $(0.1-0.2 \mathrm{~mm})$ fraction was divided into heavy- and light-mineral components with the use of tri-

Table 1. Mineral components in glacial till (grain-size: $0.1-0.2 \mathrm{~mm}$ )

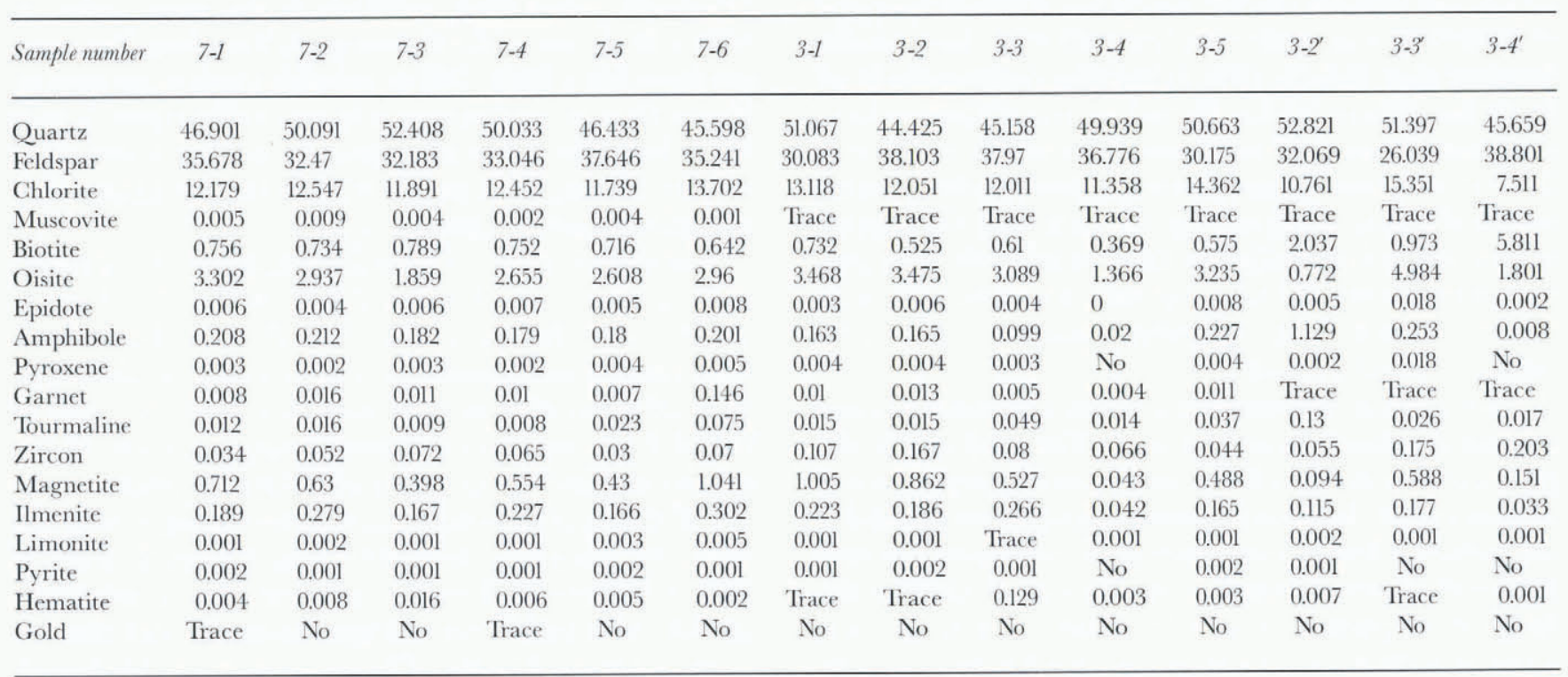


brothane (specific gravity: 2.89-2.93). Ferromagnetic minerals were further separated magnetically from the heavy fraction. The rest of the heavy fraction and the light fraction were sorted into three or four parts electromagnetically. The mineral constituents were then identified by using a binocular microscope, and occasionally with a polarizing microscope using oil immersion. The variation in mineralogy among the 14 samples collected is small (Table 1). Thus, four representative samples were selected for detailed mineralogical analysis of the respective grain-size separates.

Samples from grain-size fractions $>0.039 \mathrm{~mm}$ were impregnated and thin-sectioned. Mineral species were identified using a polarizing microscope. Grain counts were made using more than 500 grains per sample.

The $>0.039 \mathrm{~mm}$ grain-size fractions were further separated at $1 \phi$ intervals by pipette. The separate grain-size fractions were then ground into a fine powder and the mineral components were determined quantitatively by infrared spectrometer.

\section{Microfabric studies}

Sets of mutually perpendicular thin sections were prepared from the oriented impregnated samples. Microfabrics and characteristics of the comminuted mineral grains were studied by using a polarizing microscope. Sizes of over 900 primary grains and over 2700 daughter grains were measured (Table 2).

Table 2. Number of grains measured

\begin{tabular}{lcc}
\hline & Parent grains & Daughtergrains \\
\hline Quartz & 270 & $>700$ \\
Feldspar & 333 & $>1000$ \\
Chlorite & 322 & $>1000$ \\
& & \\
\hline
\end{tabular}
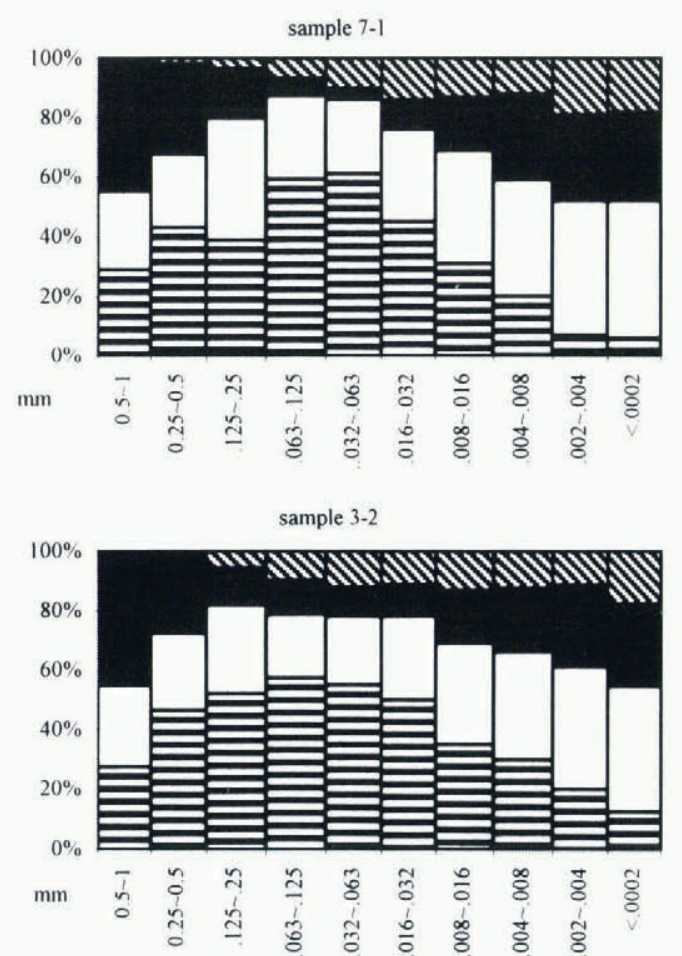

Some samples from the local bedrock, a schist, were also sectioned in order to determine mineral grain-sizes in the parent rock.

\section{RESULTS}

\section{Size distribution of quartz, feldspar and chlorite grains}

The variation in mineral content among the various size fractions is similar in the four samples (Fig. 2). Quartz dominates in the $0.125-0.031 \mathrm{~mm}$ size range. In contrast, feldspar and particularly chlorite concentrations increase relative to quartz in the smaller- and larger-size fractions.

Figure 3 shows the grain-size distribution in the bulk till samples and Figure 4 shows the grain-size distributions for quartz, feldspar and chlorite, individually, calculated from the data in Figures 2 and 3. Quartz has a preferred mode at $0.063-0.032 \mathrm{~mm}$ and in some samples a secondary mode at $0.25-0.125 \mathrm{~mm}$. Feldspar and chlorite commonly have weak modes at $0.25-0.125,0.063-0.032$ and $0.016-0.004 \mathrm{~mm}$.

\section{Crushed and abraded minerals in thin sections from oriented samples}

In thin sections prepared from the oriented impregnated samples, many grains of quartz, feldspar and chlorite appear to have been broken into two or more smaller fragments (Fig. $5 \mathrm{a}-\mathrm{g}$ ). In some cases, small quartz fragments are inferred to have been abraded from larger ones. The shapes of the edges of these grains mirror that of the larger presumed parent (Fig. 5c) and, in some places, they remain weakly connected to the parent (Fig. 5d).

Polymineralic fragments were sometimes found to be broken into monomineralic grains along mineral boundaries (Fig. 5h). Similar clasts, inferred to have resulted from crushing, were also observed in the field Cui Zhijiu and
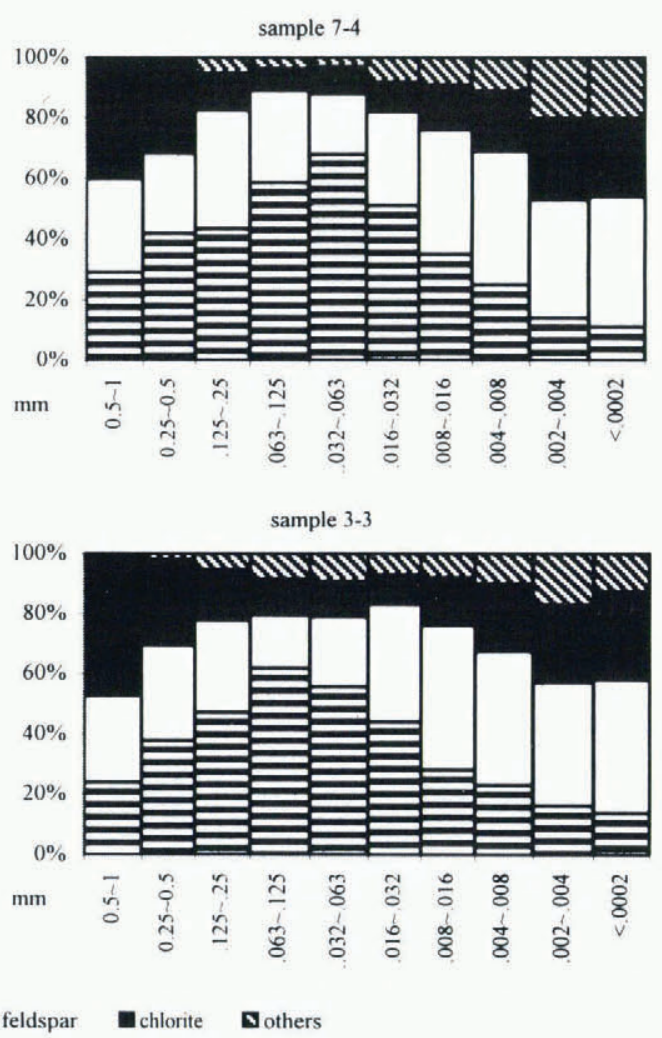

Fig. 2. Variation in mineral composition with grain-size for the four samples. 


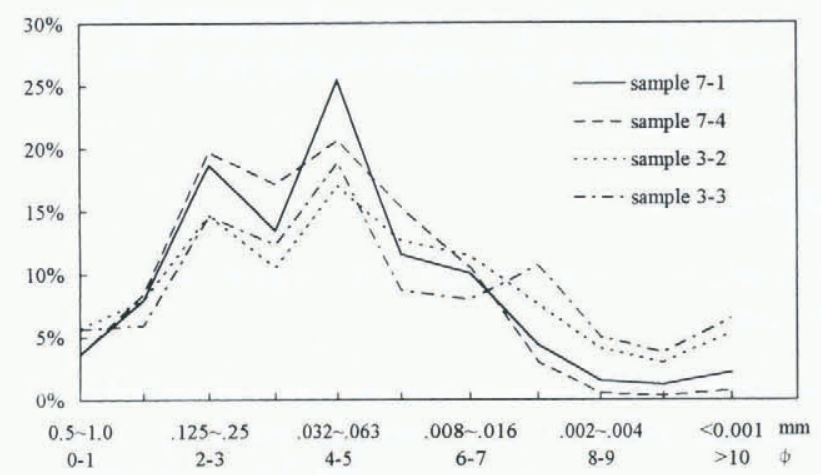

Fig. 3. Grain-size distributions of bulk samples.

others, 1992). The results that follow, however, come from analysis of monomineralic grains.

Modes in the distribution of parent grains are 0.063 $0.125 \mathrm{~mm}$ for quartz and feldspar and $0.016-0.063 \mathrm{~mm}$ for chlorite (Fig. 6a). The mode for feldspar is skewed toward smaller grain-sizes compared with quartz. The average sizes of parent grains of quartz, feldspar and chlorite are 0.129, 0.078 and $0.059 \mathrm{~mm}$, respectively, while the smallest parent grains observed were about $0.016,0.006$ and $0.002 \mathrm{~mm}$, respectively. Although the shapes of the size distributions of daughter grains are similar to those of the respective parent grains, there is a clear shift of about a factor of $2(1 \phi)$ toward finer grain-sizes (Fig. 6b). This reflects the fact that parent grains tend, most commonly, to split into two daughter fragments. The average grain-sizes thus decrease to $0.068,0.041$ and $0.024 \mathrm{~mm}$, respectively. Observed daughter fragments can be as small as $0.005 \mathrm{~mm}$ for quartz, $0.003 \mathrm{~mm}$ for feldspar and $0.0014 \mathrm{~mm}$ for chlorite.

Figure 7 shows the changes in size distribution during comminution, expressed as the percentage of the total area of a thin section occupied by grains of different sizes. Transitions from net decrease to net increase occur at $0.125,0.063$ and $0.25 \mathrm{~mm}$ for quartz, feldspar and chlorite, respectively.
The largest increases are $3.6 \%$ at $0.063-0.032 \mathrm{~mm}$ for quartz, $10.9 \%$ at $0.063-0.032 \mathrm{~mm}$ for feldspar and $10.0 \%$ at 0.032-0.016 $\mathrm{mm}$ for chlorite.

Let us define the crushing factor, $C_{\mathrm{f}}$, as the number of daughter grains resulting from crushing a parent. A crushing factor of 2 was found for $65.6 \%$ of the quartz grains, $47.2 \%$ of the feldspar grains and $40.7 \%$ of the chlorite grains (Fig. 6c). Crushing factors greater than 5 are most common for crushing events involving chlorite. In addition, for chlorite crushing factors tend to be larger for larger grain-sizes, whereas this is not so clearly the case for quartz and feldspar. The correlation coefficient for the relation between $C_{\mathrm{f}}$ and grain-size is $0.392(n=322)$ for chlorite (significant at the $0.1 \%$ level), whereas those for quartz and feldspar are only $0.150(n=270)$ and $0.167(n=333)$, respectively.

A Student's $t$-test indicates that the average sizes of parent grains of feldspar and chlorite with $C_{\mathrm{f}}=2$ are significantly smaller than the average size of the total population of parent particles of these mineral species (Fig. 6d). This property is more obvious in chlorite $($ mean $=0.033 \mathrm{~mm}$, $t=4.89, \mathrm{DF}=451$, level $=0.1 \%$, mean size of parent $=$ $0.059 \mathrm{~mm}$ ) than in feldspar (mean $=0.064 \mathrm{~mm}, t=2.87$, $\mathrm{DF}=478$, level $=5 \%$, mean size of parent $=0.078 \mathrm{~mm}$ ). In other words, smaller particles are more likely to split into only two daughter particles, whereas larger grains may split into three or more daughter particles. This is not true of quartz. On the other hand, the average sizes of daughter grains of the three minerals resulting from crushing events yielding exactly two particles are not significantly different from the average sizes of all daughter grains of these respective minerals.

\section{DISCUSSION}

The process of comminution in till probably starts with breakdown of rocks along zones of weakness, eventually resulting in monomineralic grains (Fig. 5h). These grains
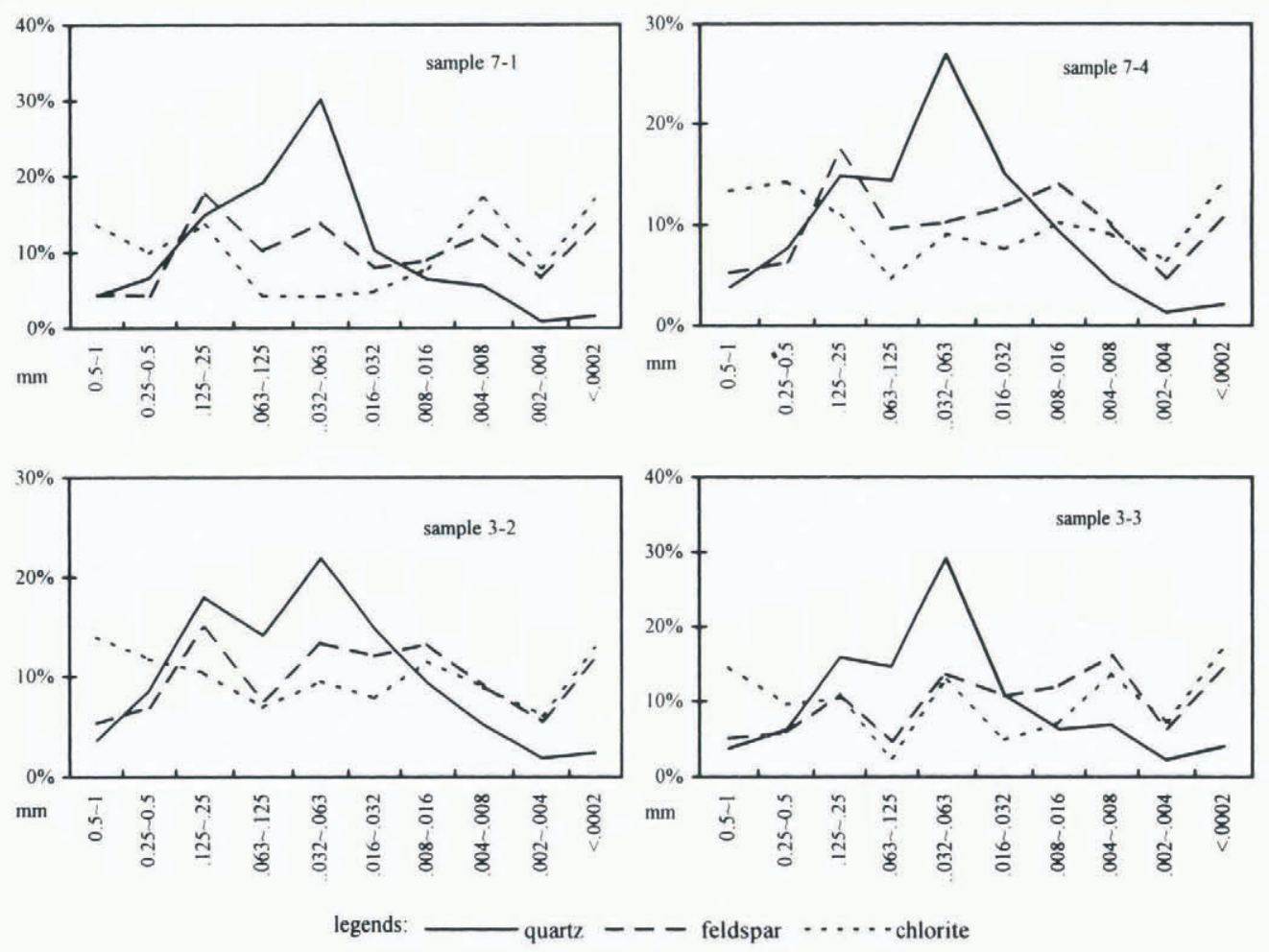

Fig. 4. Grain-size distributions of quartz, feldspar and chlorite. 


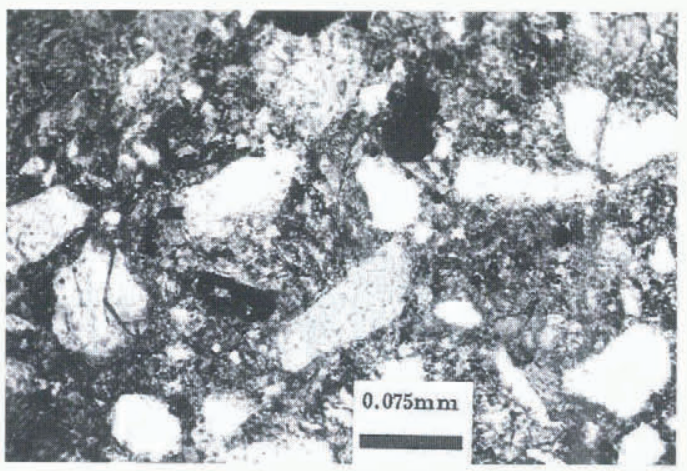

a
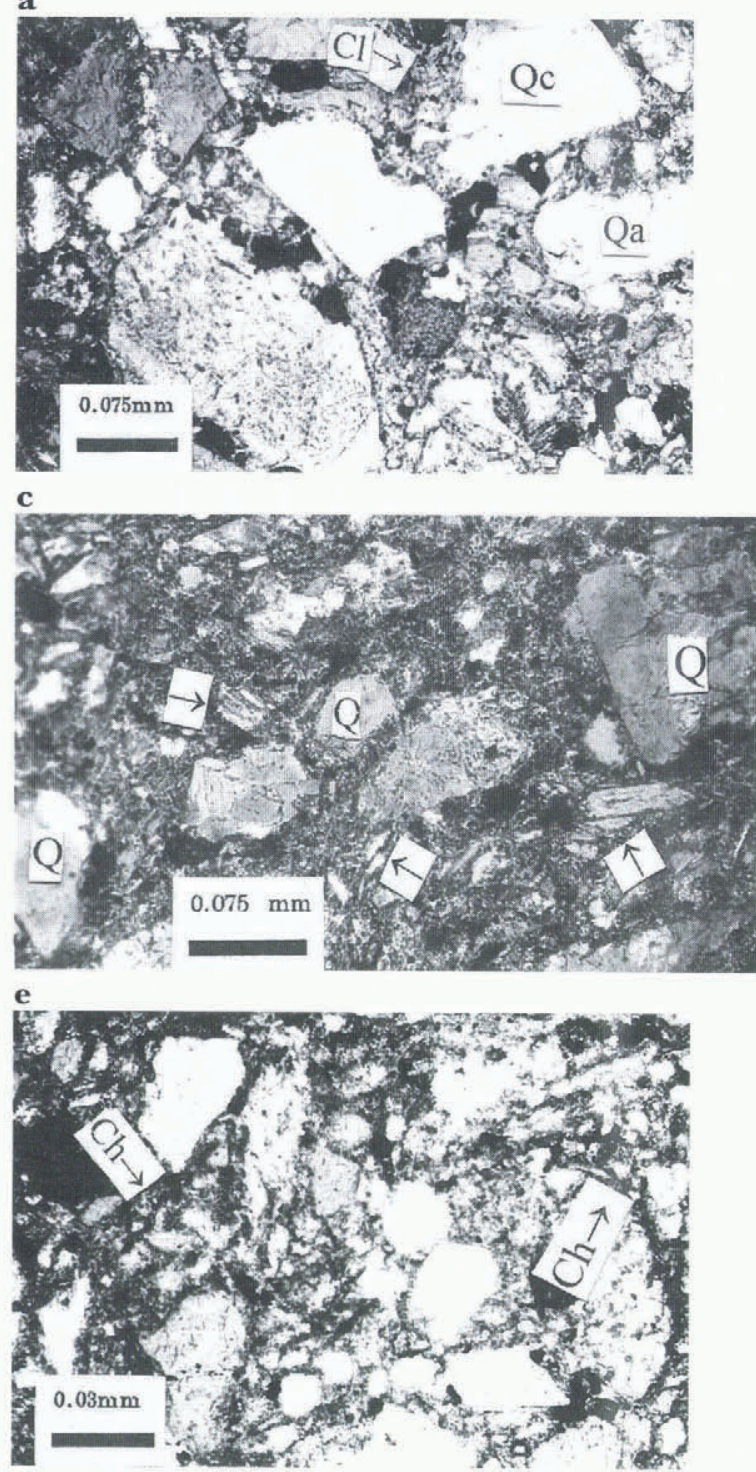

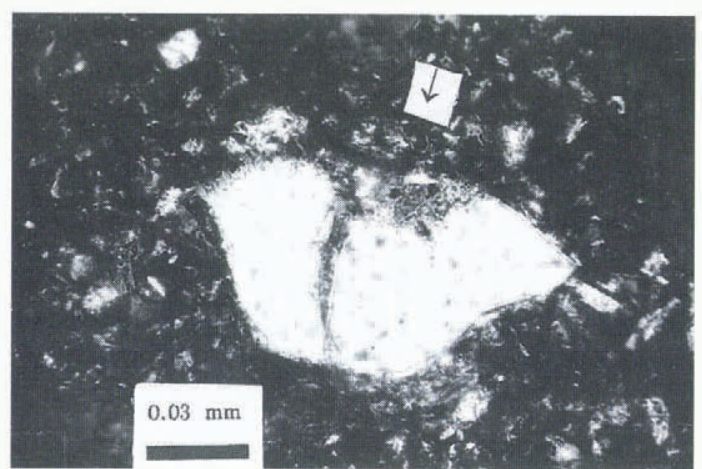

b

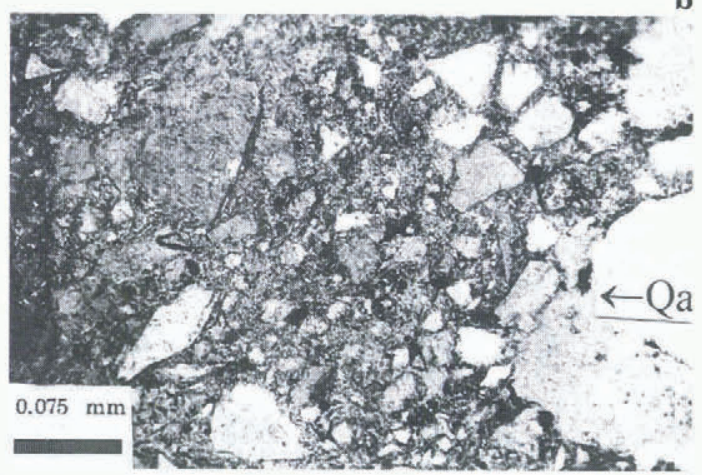

d
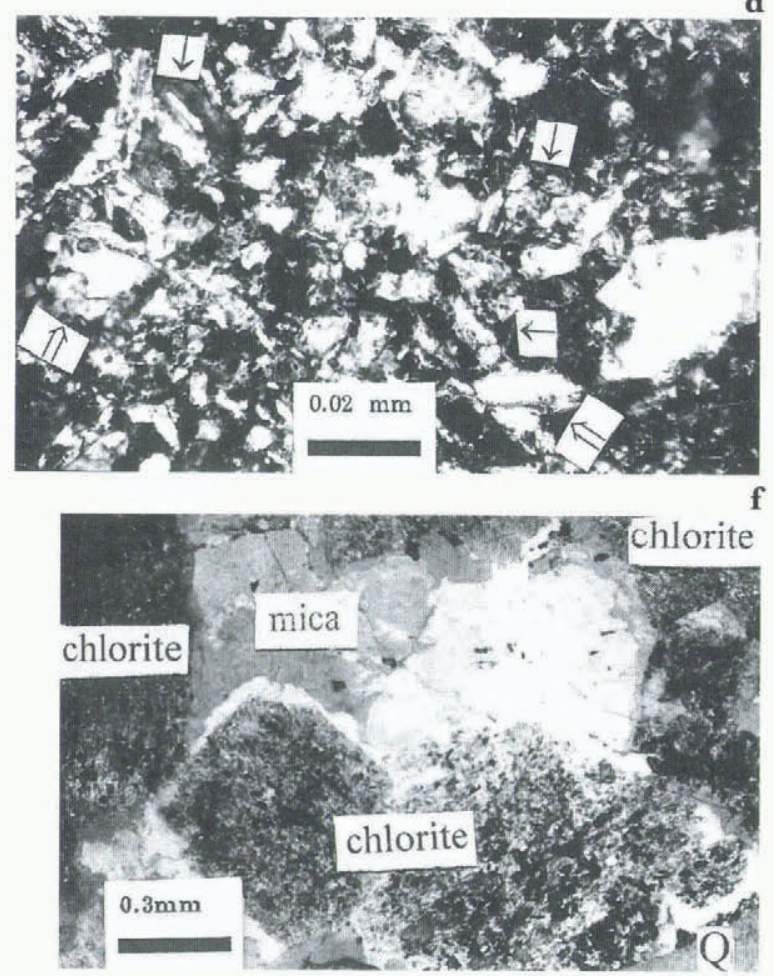

Fig. 5. (a) Quartz grains with clay rims, and two recently crushed 0.045-0.062 $\mathrm{mm}$ quartz grains (left side and upper right corner ). Under crossed nicols. The clay was formed in situ. (b) Enlargement of the crushed quartz grain in upper right corner of (a). Arrow points to clay. (c) Crushed and abraded quarlz grains. Under crossed nicols with gypsum plate. One quartz grain has been split into two smaller ones. On the right side, eight $0.04-0.05 \mathrm{~mm}$ quartz grains are inferred to have been abraded from a large one. One of the abraded grains is still weakly altached to its parent. Clay has formed on the rims of the grains. Qc, crushed quarlz grain; Qa, abraded quartz grain; Cl, clay. (d) Small quarlz grains, $0.030 .05 \mathrm{~mm}$ in diameter, are inferred to have been abraded from a larger one. Note that in the lower right corner, the edges of two small grains mirror the shape of the corresponding edge of a larger one. Qa, abraded quartz grain. Arrow points to abraded daughters. Under crossed nicols with gypsum plate. (e) Except for several large quartz grains, most of the grains are feldspar. Large ones appear to have been crushed into finer grains 0.016$0.004 \mathrm{~mm}$. Under crossed nicols with gypsum plate. Q quartz. Arrows point to crushed feldspar grains. (f) Silt grains in fine matrix. Feldspar and chlorite were still being crushed into even smaller sizes. Single arrows point to chlorite grains and double arrows to feldspar grains. Under crossed nicols. (g) Crushed small chlorite grains (Ch). Under crossed nicols with gypsum plate. (h) Part of a mineral aggregate caught in the process of being crushed into individual minerals of chlorite, mica, quartz and so forth. Under crossed nicols with gypsum plate. 

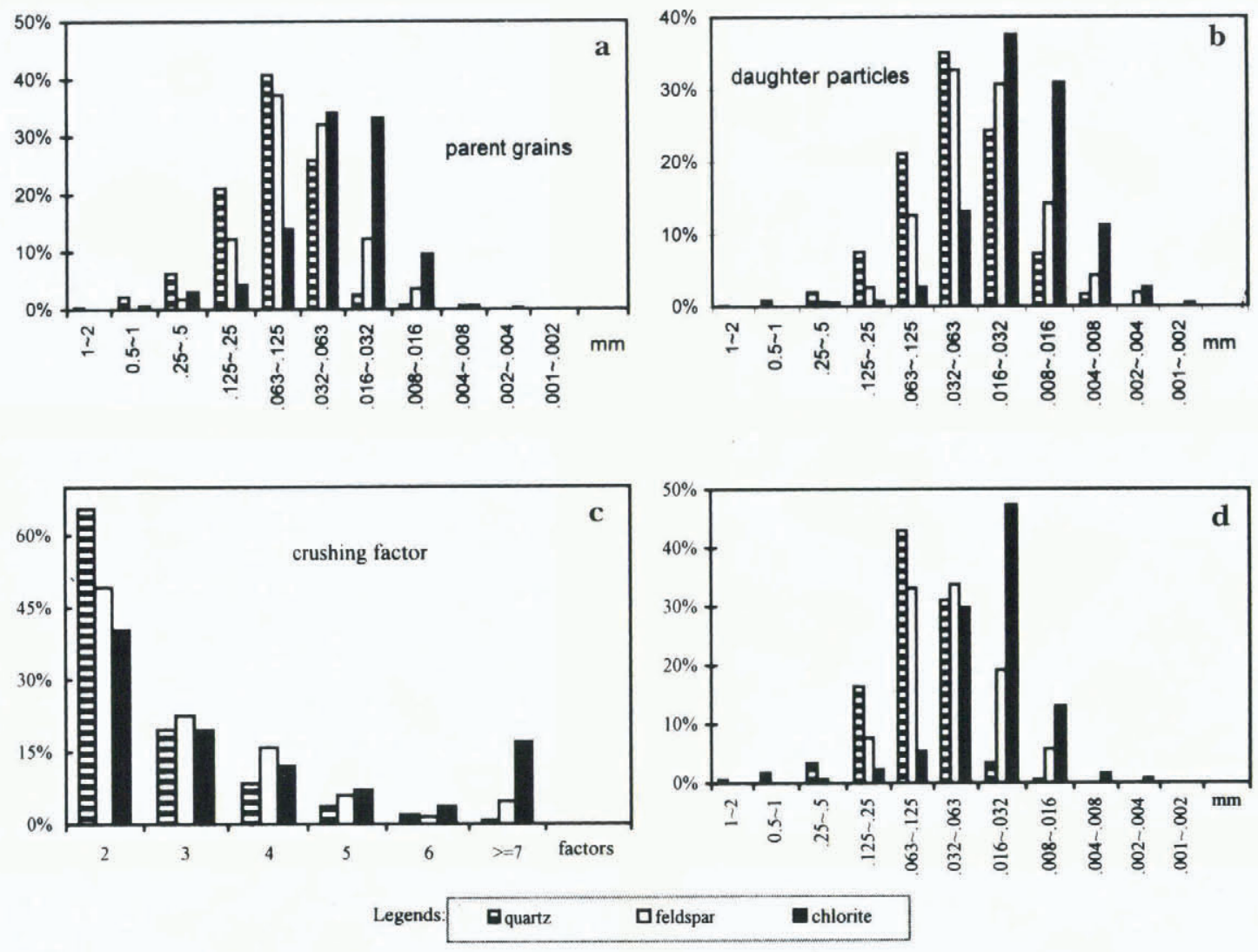

Fig. 6. (a) Grain-size distribution of parent particles. (b) Grain-size distribution of daughter particles. (c) Crushing factors, $C_{\mathrm{f}}$. (d) Size distribution of parent particles that split into exactly two daughter particles (i.e. $C_{\mathrm{f}}=2$ ).

are then split into smaller ones (Fig. $5 \mathrm{a}-\mathrm{g}$ ), perhaps eventually reaching a terminal grade or crushing limit.

The common secondary modes at $0.25-0.125 \mathrm{~mm}$ in the grain-size distributions of quartz and feldspar (Fig. 4) come from the parent schists which have crystals of this size. Similarly, chlorite is relatively abundant in the $1.0-0.125 \mathrm{~mm}$ size range because chlorite crystals are large in the schists.

For quartz, the greatest increase in the number of grains, expressed in per cent by area, occurs in the size category $0.032-0.063 \mathrm{~mm}$ (Fig. 7). Consistent with the work of Dreimanis and Vagners (1971), this results in a mode in the grain-size distributions in this size range (Fig. 4). This mode,

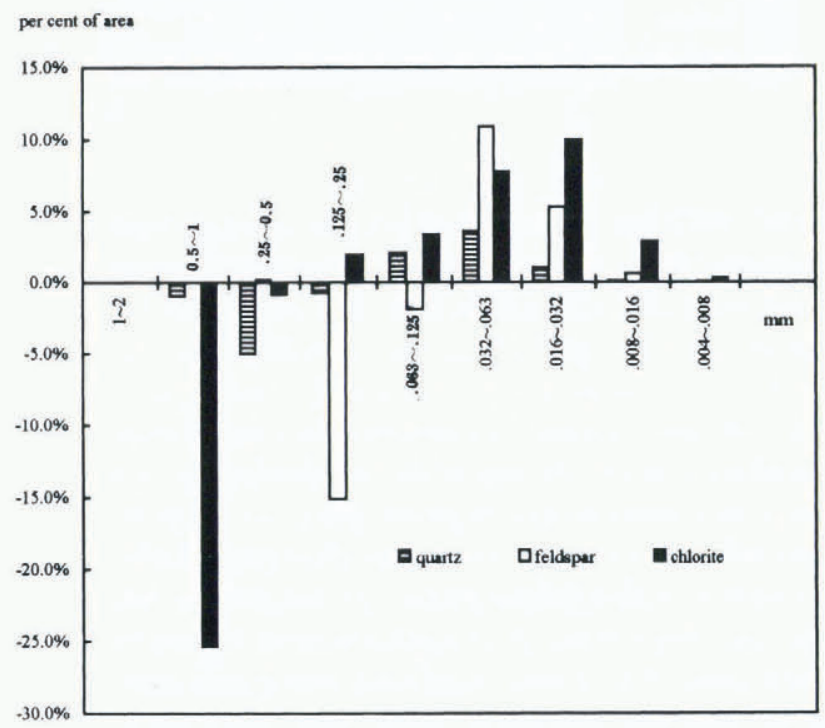

Fig. 7. Increments of grain-size percentage after crushing . however, is not the lower limit of crushing or abrasion; rather it is a preferred daughter grain-size.

Feldspar is weaker than quartz, in part because it has three cleavage directions. Thus, it is crushed more readily, as shown by the larger changes in size distribution compared with quartz (Fig. 7). Furthermore, crushing of feldspar yields a wider range of grain-sizes with more fine material and no clearly dominant mode below $0.063 \mathrm{~mm}$ (Fig. 4).

Chlorite is quite weak and has a well-developed cleavage. Thus, it is readily crushed. The decrease in chlorite grains in the $0.5-1.0 \mathrm{~mm}$ size range is the largest observed (Fig. 7) and, consistent with grinding experiments summarized by Drewry (1986), the daughter grains vary widely in size (Figs $6 \mathrm{~b}$ and 7). The strong positive relation between $C_{\mathrm{f}}$ and grain-size of chlorite, mentioned earlier, reflects the fact that larger chlorite grains are likely to be crushed into many small fragments rather than fewer large ones.

For feldspar and chlorite the maximum increases in Figure 7 appear to be in the $0.032-0.063$ and $0.016-0.032 \mathrm{~mm}$ size categories, respectively. However, the lack of distinct modes at these sizes in Figure 4 suggests that these are not preferred daughter sizes. Rather, the preferred sizes may be as low as $0.016-0.004$ or even $0.002 \mathrm{~mm}$ (Fig. 4), and thus not detectable given the limits of resolution of thin sections and the optical microscope.

Some failures involve detachment of one or several quite small fragments from the rims of a parent (Fig. $5 \mathrm{c}$ and d). These surficial failures are most common on larger grains. It is inferred that they are due to particle-particle interactions that are dominated by shear forces rather than by normal forces. The term abrasion may be appropriate for this process, although any distinction between abrasion and crushing is likely to be arbitrary. Micro-shears that could 
result in such failures have been observed in till in scanning electron-microscope studies (Love and Derbyshire, 1985) and in optical microscope studies using thin sections (van der Meer, 1990; Yi Chaolu, 1992). Because such failures are most common on larger grains, they are most commonly observed on quartz.

\section{CONGLUSIONS}

Mineral properties determine grain-size distributions of individual minerals in till. During comminution, parent grains of quartz and feldspar tend to break into two daughter particles of roughly equal size, whereas chlorite grains, particularly the larger ones, break into more than two daughter particles. There appears to be a preferred daughter grain-size for quartz of about $0.05 \mathrm{~mm}$. In contrast, for feldspar and chlorite the preferred daughter grain-size is less distinct, and may be quite small as these weaker minerals are more abundant than quartz in the fine-silt and clay fractions.

Failures resulting in a small number of daughter particles of roughly equal size are far more common than ones yielding several very small daughter particles and a large residual parent. To the extent that the former process is associated with normal stresses and the latter with shear stresses, crushing appears to be more common than abrasion. This has implications for understanding deformation mechanisms in till.

\section{ACKNOWLEDGEMENTS}

The author thanks Lady W. Zhu, senior laboratory technician at the Department of Geology of Peking University, for infrared spectrometer analysis, Zhijiu Cui, Professor at the Department of Geography of Peking University, for valuable suggestions, R. LeB. Hooke for revision of the manuscript, and R. LeB. Hooke, N. Iverson and M. Sharp for valuable suggestions in revising the paper. This paper has been supported by Natural Science Foundation of China grant No. 49501003 and Tianshan Glacier Observatory grant No. 9402.

\section{REFERENCES}

Boulton, G. S. 1978. Boulder shapes and grain-size distributions as indicators of transport paths through a glacier and till genesis. Sedimentology, 25(6), $773-799$.

Cui Zhijiu, Yi Chaolu and Yan Jinfu. 1992. [Quaternary glaciations in the Halasi river catchment and its surroundings in the Altai Mountains in Xingjiang.] f. Glaciol. Geocryol., 14(4),342-351. [In Chinese with English summary.]

DiLabio, R. N.W. 198I. Glacial comminution of chalcopyrite. Geol. Surv. Can. Bull. 323.

Drake, L. D. 1972. Mechanisms of clast attrition in basal till. Geol. Soc. Am. Bull., 83, $2159-2165$.

Dreimanis, A. and U.J. Vagners. 1971. Bimodal distribution of rock and mineral fragments in basal tills. In Goldthwait, R. P., ed. Till: a symposium. Columbus, OH, Ohio State University Press, 237250.

Dreimanis, A. and U. J. Vagners. 1972. The effect of lithology upon texture of till. In Yatsu, E. and A. Falconer, eds. Research Methods in Pleistocene Geomorphology. Proceedings: 2nd Guelph Symposium on Geomorphology, 1971. Norwich, England, Geo Abstracts Ltd., 66-82.

Drewry, D. 1986. Glacial geologic processes. London, Edward Arnold.

Haldorsen, S. 1981. Grain-size distribution of subglacial till and its relation to glacial crushing and abrasion. Boreas, $10(1), 91-105$.

Krinsley, D. H. and J. C. Doornkamp. 1973. Atlas of quartz sand surface textures. Cambridge, Cambridge University Press.

Love, M. A. and E. Derbyshire. 1985. Microfabric of glacial soils and its quantitative measurement In Forde, M. C., ed. Proceedings, International Conference on Construction in Glacial Tills and Boulder Clays, 12-14 March 1985, Edinburgh, Scotland. English Technical Press.

Mahaney, W. C., W. Vortisch and P. Julig. 1988. Relative differences between glacially crushed quartz transported by mountain and continental ice - some examples from North America and East Africa. Am. J. Sci., $288(8), 810-826$.

Van der Meer, J.J. M. 1990. Micromorphology of some North Sea till samples a pilot study. J. Quat. Sci., 5 (2), 95-101.

Yi Chaolu. 1992. [Physico-chemical processes of ice bed interface and microfabric of till, the Halasi river catchment, the Altai Mountains and the source region of the Urumqi river, the Tianshan Mountains.] (Ph.D. thesis, Peking University.) [In Chinese.]

Yi Chaolu and Cui Zhijiu. 1994. [Classification and sedimentary types of glacial lakes in the Halasi river catchment, the Altai Mountains.] Oceanologia et Limnologia Sinica, 23 5), 477-485. [In Chinese with English abstract.] 